\title{
Collateral consequences of an ever-expanding prison system
}

$\mathrm{S}$

upporters of Canada's Conservative government's plan to spend more than $\$ 235$ million on expanding federal correctional facilities argue that enlarging Canada's penitentiaries is "the cost of a safe and secure society." While this a worthy goal, this view fails to recognize that prisoners, most of whom serve less than a month in custody, are a part of society. Instead of incarcerating and later releasing more marginalized and at-risk Canadians, much could be gained by supporting the reintegration of those already in the system.

A large body of evidence now points to the merits of keeping people out of prison through therapeutically oriented diversion programs, and to evidencebased infection control measures for the approximately 37000 people held in secure custody in Canada on any given day. However, there has been precious little consideration of the much larger group - around 82000 - exiting the prison system each year. Although complete data on recidivism in Canada are not publicly available, studies suggest that the majority of ex-prisoners reoffend, typically within two years. Illicit drug use is a key, modifiable risk factor for recidivism.

Among ex-prisoners, illicit drug use is also a key driver of morbidity and mortality. Record linkage studies from the United States, United Kingdom Australia and elsewhere have shown that prisoners are at massively increased risk of death following release, most commonly due to drug overdose and suicide. Remarkably, there has been no investigation of mortality outcomes for ex-prisoners in Canada, however there is no reason to suspect that findings would be different.

Similarly, longitudinal studies in the US, Australia and elsewhere have documented significant morbidity in cohorts of ex-prisoners, including injection drug use, infectious disease and mental illness. Although Canadian policy-makers have yet to show a similar interest in their own growing population of ex- prisoners, evidence from a cohort of over 1500 drug users in Vancouver suggests a similar pattern. Among this group, the $35 \%$ with a history of incarceration are more likely to have experienced nonfatal drug overdose ${ }^{1}$ and HIV infection $^{2}$ and, among those who are seropositive, reduced HIV treatment adherence. ${ }^{3}$ These adverse health out-

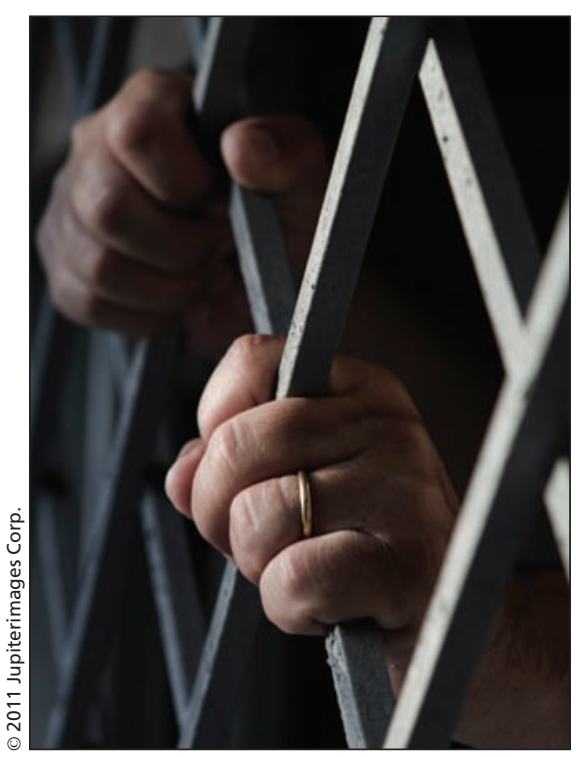

comes are common and preventable, and affect not only the ex-prisoner but also their family and community.

By law, alongside its role carrying out sentences imposed by the courts, the job of Canada's correctional system is to assist in the rehabilitation of offenders and their reintegration into society postrelease. Although the health of many prisoners may improve while in custody, the real challenge is sustaining and building on these gains once prisoners return to the community. In the absence of robust data on health outcomes for ex-prisoners in Canada, it is not possible to evaluate the success (or otherwise) of current practices. Policy-makers lack the tools to hold the correctional system accountable.

However, studies from abroad have demonstrated that evidence-based programs can improve health outcomes for ex-prisoners. For those interested in the health of these marginalized individuals, this is good news. Fortunately, for those more interested in getting "tough on crime," this is still good news: there is growing evidence that improvements in health and reductions in drug use are associated with reduced risk of re-offending. ${ }^{4}$

This rare convergence of public health and criminal justice goals presents a unique opportunity. Proper investment in these programs can have a meaningful impact on health outcomes for ex-prisoners, public health more broadly and, with reduced offending as a corollary, improved public safety. Rather than further expanding the prison system to accommodate those that the system has failed, the Harper government could better serve the Canadian public by supporting the reintegration of those already in the system. Surely this is a more equitable, evidence-based way to achieve a "safe and secure society."

\section{Stuart A. Kinner PhD}

Centre for Population Health

Burnet Institute

Melbourne, Australia

M-J Milloy MSc

British Columbia Centre for Excellence in HIV/AIDS

St. Paul's Hospital

Vancouver, BC

\section{References}

1. Kerr T, Fairbairn N, Tyndall M, et al. Predictors of non-fatal overdose among a cohort of polysubstance-using injection drug users. Drug Alcohol Depend 2007;87:39-45.

2. Werb D, Kerr T, Small W, et al. HIV risks associated with incarceration among injection drug users implications for prison-based public health strategies. J Public Health (Oxf) 2008;30:126-32.

3. Palepu A, Tyndall MW, Chan K, et al. Initiating highly active antiretroviral therapy and continuity of HIV care: the impact of incarceration and prison release on adherence and HIV treatment outcomes. Antivir Ther 2004:9:713-9.

4. Lattimore PK, Visher CA. The multi-site evaluation of SVORI: Summary and synthesis: The multisite evaluation of the Serious and Violent Offender Reentry Initiative. Washington (DC): National Institute of Justice; 2009

Acknowledgement: The authors thank Dr. Thomas Kerr for his helpful comments on an earlier version of this manuscript.

CMAJ 2011. DOI:10.1503/cmaj.101848 